\title{
Reversibly Increased Lymphocyte Response to Mitogens in a Young Man with Isolated Adrenocorticotropic Hormone Deficiency
}

\author{
Mari Kimura, Shun-ichi Tanaka, Tadashi Yamakawa, Ran Tachinara, \\ Tatsuya SaItoh, Yumiko Yamaguchi and Hisahiko SeKinara
}

\begin{abstract}
A 21-year-old man with isolated adrenocorticotropic hormone (ACTH) deficiency complained of loss of consciousness in association with hypoglycemia. Both plasma ACTH and cortisol levels were low and failed to respond to corticotropin-releasing hormone (CRH) stimulation. The patient also showed abnormal findings in hematological examination, such as neutropenia and anemia with lymphocytosis, activity of coagulation factors, and electroencephalography (EEG). Furthermore, mitogen-induced lymphocyte proliferation was increased. After successful replacement therapy with hydrocortisone $15 \mathrm{mg} / \mathrm{day}$, most of these abnormalities including the lymphocyte proliferation were fully restored.
\end{abstract}

(Internal Medicine 36: 194-197, 1997)

Key words: adrenocorticotropic hormone (ACTH) deficiency, lymphocyte proliferation, glucocorticoid

\section{Introduction}

Isolated adrenocorticotropic hormone (ACTH) deficiency has been reported to occur commonly in adult men (1). In the present study, we report a case of isolated ACTH deficiency in a young male whose lymphocyte response to mitogens was markedly increased.

\section{Case Report}

A 21-year-old man was admitted to hospital with the complaint of an episode of loss of consciousness in association with hypoglycemia (blood glucose $38 \mathrm{mg} / \mathrm{dl}$ ), fever, and incontinence. Although no specific family or past medical history was identified, the patient's family mentioned that he gradually became less active from age 15 and had no work since finishing high school.

On admission, he was $169.3 \mathrm{~cm}$ tall and weighed $51.7 \mathrm{~kg}$, blood pressure was $94 / 50 \mathrm{mmHg}$, pulse rate was $88 / \mathrm{min}$, regular. In general status, pubic hair was sparse and bilateral testes were small. Face color and conjunctivae were normal. Thyroid gland was not swollen. There was no specific abnormal finding in chest, abdomen, and extremities. There was no neurological abnormality. Leukocyte count was $6,000 / \mu 1$, both neutropenia and lymphocytosis (seg $28.5 \%$, lym $56.3 \%$ ) were identified. Hematological test also revealed mild anemia (erythrocyte count $4.08 \times 10^{4} / \mu \mathrm{l}$, mean corpuscular volume $(\mathrm{MCV})$ $85.1 \mu \mathrm{m}^{3}$, mean corpuscular hemoglobin (MCH) $28.5 \mathrm{pg} / \mathrm{cell}$, mean corpuscular hemoglobin concentration (MCHC) 33.5\%, hemoglobin $11.9 \mathrm{~g} / \mathrm{dl}$, hematocrit $34.7 \%$ ). Blood chemistries revealed a slightly increased concentration of muscle-derived enzymes (lactate dehydrogenase $533 \mathrm{IU} / l$, creatine kinase 385 $\mathrm{IU} / l$ ). Prothrombin time (PT) and activated partial thromboplastin time (APTT) were prolonged and coagulation factors, 5th, 9th, 11th and 12th, were low (Table 1). As shown in Table 2, both plasma ACTH and cortisol were significantly decreased whereas plasma thyrotropin (TSH) and prolactin (PRL) were normal. The circadian rhythm was not identified in the levels of both ACTH and cortisol. Head-computed tomography (CT), magnetic resonance imaging (MRI), and abdominal CT revealed no abnormal finding. Electroencephalography (EEG) showed that basic rhythm was $7-8 \mathrm{~Hz}, \theta-\alpha$ rhythm mixed with $\theta$ wave, which has been reported in other cases with ACTH deficiency $(2,3)$. Thus, isolated ACTH deficiency was sus-

From the Third Department of Internal Medicine, Department of Medicine and *the Third Internal Medicine, Department of Medicine, Yokohama City University, Yokohama

Received for publication January 26, 1996; Accepted for publication December 9, 1996

Reprint requests should be addressed to Dr. Shun-ichi Tanaka, the Third Department of Internal Medicine, Yokohama City University School of Medicine, 3 9 Fuku-ura, Kanazawa-ku, Yokohama 236 
Table 1. Blood Coagulation Analysis

Activities

\begin{tabular}{ccc}
\hline & before therapy & after therapy \\
\hline PT (INR) & 1.46 & 1.29 \\
APTT (sec.) & 44.9 & 37.9 \\
\hline
\end{tabular}

PT: prothrombin time, APTT: activated partial thromboplastin time, INR: international normalized ratio.

Coagulation factors

\begin{tabular}{rcc}
\hline & before therapy & after therapy \\
\hline 5 th $(\%)$ & 61.0 & 51.4 \\
9 th $(\%)$ & 76.0 & 52.8 \\
11 th $(\%)$ & 75.4 & 92.4 \\
12 th $(\%)$ & 69.6 & 78.9 \\
\hline
\end{tabular}

Table 2. Endocrinological Findings

\begin{tabular}{lcc}
\hline & before the therapy & after the therapy \\
\hline ACTH $(\mathrm{pg} / \mathrm{ml})$ & 8 & 10 \\
TSH $(\mu \mathrm{U} / \mathrm{ml})$ & 9.3 & 3.2 \\
$\mathrm{LH}(\mathrm{mIU} / \mathrm{ml})$ & 4.8 & 3.7 \\
FSH $(\mathrm{mIU} / \mathrm{ml})$ & 2.5 & 2.7 \\
GH $(\mathrm{ng} / \mathrm{ml})$ & 0.28 & 0.47 \\
PRL $(\mathrm{ng} / \mathrm{ml})$ & 15.1 & 9.3 \\
Cortisol $(\mu \mathrm{g} / \mathrm{dl})$ & $<1.0$ & 11.6 \\
Aldosterone $(\mathrm{ng} / \mathrm{dl})$ & 21 & 30 \\
DHEA $(\mathrm{ng} / \mathrm{dl})$ & 273.0 & 659.0 \\
Testosterone $(\mathrm{ng} / \mathrm{dl})$ & 537 & 702 \\
PRA $(\mathrm{ng} / \mathrm{ml} / \mathrm{h})$ & 1.00 & 3.90 \\
\hline
\end{tabular}

ACTH: adrenocorticotropic hormone, TSH: thyroid-stimulating hormone, LH: luteinizing hormone, FSH: follicle-stimulating hormone, GH: growth hormone, PRL: prolactin, DHEA: dehydroepiandrosterone, PRA: plasma renin activity.

Diurnal rhythm of cortisol and $\mathrm{ACTH}$

\begin{tabular}{lccc}
\hline & $06: 00$ & $16: 00$ & $24: 00$ \\
\hline Cortisol $(\mu \mathrm{g} / \mathrm{dl})$ & $<1.0$ & $<1.0$ & $<1.0$ \\
$\mathrm{ACTH}(\mathrm{pg} / \mathrm{ml})$ & 8 & 7 & 6 \\
\hline
\end{tabular}

pected in this case. The results of various endocrinological stimulation tests are shown in Table 3: plasma cortisol did not respond in the rapid $\mathrm{ACTH}$ test, and both plasma $\mathrm{ACTH}$ and cortisol did not increase in response to the corticotropinreleasing hormone (CRH) stimulation. However, plasma corti-
Table 3. Results of Stimulation Tests

1. Rapid ACTH test (tetracosactide acetate $250 \mu \mathrm{g}$ i.v.)

\begin{tabular}{lccc}
\hline Time $(\min )$ & 0 & 30 & 60 \\
\hline Cortisol $(\mu \mathrm{g} / \mathrm{dl})$ & $<1.0$ & $<1.0$ & $<1.0$ \\
\hline
\end{tabular}

2. CRH test (human corticorelin $100 \mu \mathrm{g}$ i.v.)

\begin{tabular}{lccccccc}
\hline Time $(\min )$ & 0 & 15 & 30 & 45 & 60 & 90 & 120 \\
\hline Cortisol $(\mu \mathrm{g} / \mathrm{dl})$ & $<1.0$ & $<1.0$ & $<1.0$ & $<1.0$ & $<1.0$ & $<1.0$ & $<1.0$ \\
ACTH $(\mathrm{pg} / \mathrm{ml})$ & 7 & $<5$ & 6 & $<5$ & $<5$ & $<5$ & $<5$ \\
\hline
\end{tabular}

3. Standard ACTH test (tetracosactide acetate $1 \mathrm{mg}$ i.m. for 3 days)

\begin{tabular}{llccc}
\hline & 0 day & 1 day & 2 day & 3 day \\
\hline Urine 17-OHCS (mg/day) & $<0.02$ & 0.53 & 3.52 & 9.05 \\
Urine cortisol $(\mu \mathrm{g} /$ day $)$ & 11.53 & 14.6 & - & 81.9 \\
Plasma cortisol $(\mu \mathrm{g} / \mathrm{dl})$ & $<1.0$ & 2.6 & 9.1 & 18.4 \\
\hline
\end{tabular}

4. TRH, LH-RH test (protirelin $500 \mu \mathrm{g}$ i.v. and gonadorelin acetate 100 $\mu \mathrm{g}$ i.v.)

\begin{tabular}{lcrrrrrc}
\hline Time (min) & 0 & 15 & 30 & 60 & 90 & 120 & 180 \\
\hline LH $(\mathrm{mIU} / \mathrm{ml})$ & 6.0 & 14.6 & 17.9 & 16.8 & 15.2 & 12.8 & 11.2 \\
FSH $(\mathrm{mIU} / \mathrm{ml})$ & 2.7 & 3.9 & 4.1 & 4.3 & 4.2 & 4.1 & 3.8 \\
TSH $(\mu \mathrm{U} / \mathrm{ml})$ & 4.5 & 19.9 & 23.9 & 19.8 & 16.0 & 12.4 & - \\
PRL $(\mathrm{ng} / \mathrm{ml})$ & 9.8 & 41.8 & 35.2 & 28.4 & 20.4 & 15.3 & - \\
\hline
\end{tabular}

sol, and urinary excretion of cortisol and 17-hydroxycorticosteroid (17-OHCS) increased in the 3-day ACTH test. Plasma TSH and plasma PRL responses in the TRH test and LH response in the LH-RH test were all normal whereas plasma FSH response in the LH-RH test was low. Plasma testosterone level was normal (Table 2).

This case was, thus, diagnosed as isolated ACTH deficiency, and treated with glucocorticoid (hydrocortisone $15 \mathrm{mg}$ /day). In response to the replacement therapy, neutropenia, lymphocytosis, and anemia were all restored and normalized. PT and APTT were also normalized. Among coagulation factors reduced at baseline, 11 th and 12th factors were restored, whereas 5 th and 9th were still low (Table 1). As shown in Fig. 1, mitogeninduced lymphocyte proliferation, which was increased at baseline, was decreased after replacement therapy. Both plasma glucose and insulin response in $75 \mathrm{~g}$ oral glucose tolerance test (OGTT) were also normalized (Fig. 2). As for the endocrine abnormalities, basal plasma TSH and PRL levels were normalized, and PRA was increased (Table 2). The results of LH-RH test and TRH test were not changed after the treatment. EEG was normalized with 9-10 Hz basic rhythm slightly mixed 


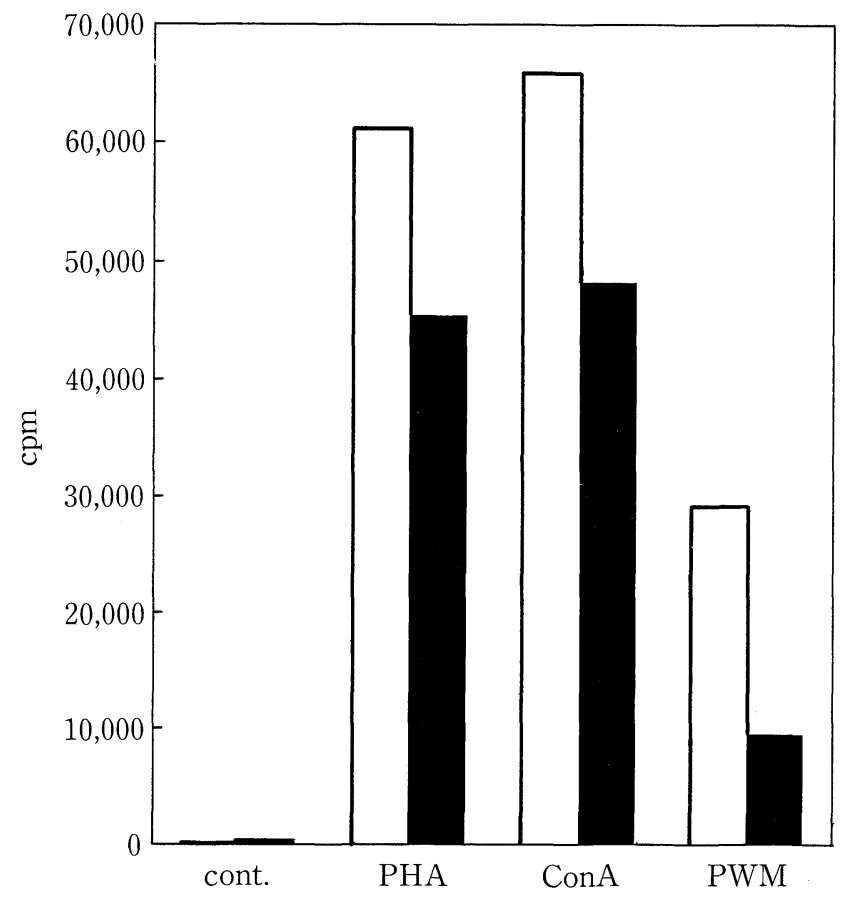

Figure 1. Mitogen-induced lymphocyte proliferation. Open bar and closed bar represent ${ }^{3} \mathbf{H}$-thymidine uptake of lymphocytes before and after glucocorticoid replacement therapy, respectively. ConA: concanavalin A, PHA: phytohemagglutinin, PWM: pokeweed mitogen.

with $\theta$ wave. The patient is currently followed up with hydrocortisone $15 \mathrm{mg} / \mathrm{day}$.

\section{Discussion}

We report on a case of isolated ACTH deficiency in a young man. Successful glucocorticoid replacement therapy restored both his daily activities and laboratory findings. It is known that isolated ACTH deficiency is often associated with many abnormal findings other than those of pituitary-adrenal axis: anemia (4), elongation of PT and APTT (5), neutropenia, lymphocytosis (6), and abnormal EEG (2). This case also showed such findings as neutropenia, lymphocytosis, mild anemia, increased levels of muscle-derived enzymes, and abnormal EEG. However, there have been no reports on an abnormality of immunological function in isolated ACTH deficiency. In this study, we examined cellular immunity and demonstrated that mitogeninduced lymphocyte proliferation was increased in the patient. These enhancements were normalized after successful glucocorticoid replacement therapy, suggesting that these abnormal lymphocyte function may be attributable to chronic cortisol deficiency. Glucocorticoids have been reported to have suppressive effects on lymphocyte functions (7). For example, although the mechanism is not well understood, glucocorticoids alter the circulating population of white blood cell resulting in monocytopenia and lymphocytopenia (8-10). Glucocorticoids are also known to inhibit the production of IL-2, which is an

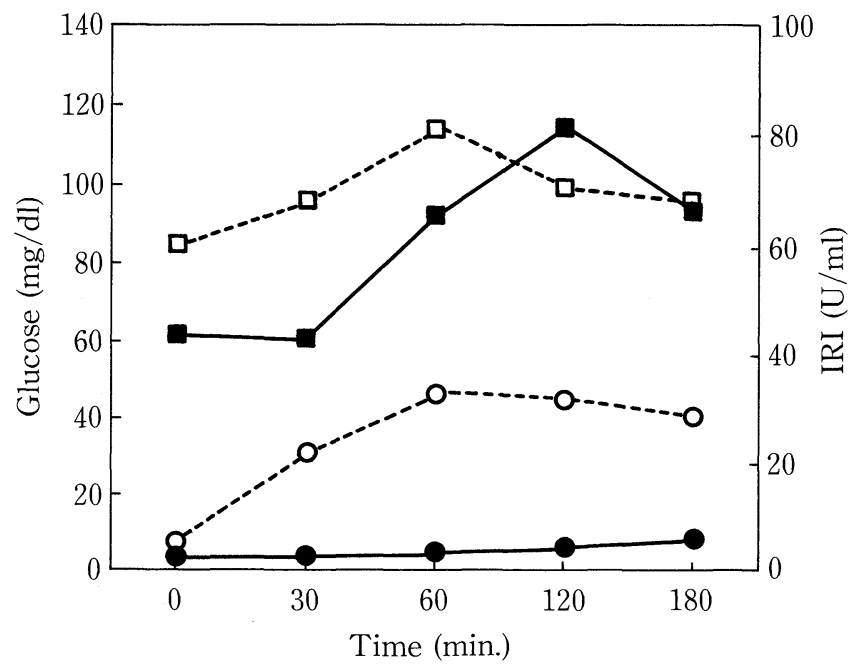

Figure 2. 75 g OGTT. Solid square ( $\square$ ) and open square ( $\square$ ) represent blood glucose concentrations before and after glucocorticoid replacement therapy, respectively. Solid circle (O) and open circle $(O)$ represent plasma insulin levels (IRI) before and after glucocorticoid replacement therapy, respectively.

important $\mathrm{T}$ cell growth factor (11-13). Recently, it was suggested that nuclear factor kappa B (NF- $\kappa \mathrm{B})$, a regulator of immune system and inflammation, may be a target for glucocorticoid-mediated immunosuppression $(14,15)$. In this context, the increased lymphocyte proliferation reported here may be attributable to long-term deficiency of glucocorticoid.

In this case, prothrombin time and activated partial thromboplastin time were prolonged, and 5th, 9th, 11th and 12th coagulation factors were low. After replacement therapy, however, 11 th and 12th factors were restored whereas 5th and 9th were still low. There was a recent report on abnormality of coagulation factors in isolated ACTH deficiency (16).

In summary, we reported a case of isolated ACTH deficiency in a young man whose mitogen-induced lymphocyte proliferation was increased and decreased with successful glucocorticoid replacement therapy.

\section{References}

1) Hashimoto K. Isolated ACTH deficiency. Chiryo 74: 1639, 1992 (in Japanese).

2) Fukada M, Takahashi K, Kitagawa T. EEG changes of an isolated deficiency associated with adrenocorticotrophic hormone. A study of two cases with a review of the Japanese literature. Shinkei Naika 17: 144, 1982 (in Japanese).

3) Hironaka M, Murakami K, Takeda S, et al. A case of isolated deficiency of ACTH with reversible hypothyroidism, which was discovered by the episode of hypoglycemic delirium. Hiroshima Igaku 43: 979, 1990 (in Japanese).

4) Stacpoole PW, Interlandi JW, Nicholson WE, et al. Isolated ACTH deficiency: a heterogeneous disorder. Critical review and report of four new cases. Medicine 61: 13, 1982.

5) Watanabe K, Omura M, Sugimoto T, et al. A case of adult isolated ACTH deficiency with decrease of platelet. Hormone to Rinsho 43: 28, 1994 (in Japanese). 


\section{Lymphocyte Response in ACTH Deficiency}

6) Matsukura S. Hypopituitarism. Gendai Iryo 26: 299, 1994 (in Japanese).

7) Bateman A, Singh A, Kral T. The immune-hypothalamic-pituitaryadrenal axis. Endocr Rev 10: 92, 1989.

8) Fauci AS, Dale DC. The effects of in vivo hydrocortisone on subpopulations of human lymphocytes. J Clin Invest 53: 240, 1974.

9) Fauci AS. Mechanisms of corticosteroid action on lymphocyte subpopulations. II. Differential effects of in vivo hydrocortisone, prednisone and dexamethasone on in vitro expression of lymphocyte function. Clin Exp Immunol 24: 54, 1976.

10) Fauci AS. Mechanisms of corticosteroid action on lymphocyte subpopulations. I. Redistribution of circulating $\mathrm{T}$ and $\mathrm{B}$ lymphocytes to the bone marrow. Immunology 28: 669, 1975.

11) Kelso A, Munck A. Glucocorticoid inhibition of lymphokine secretion by alloreactive T lymphocyte clones. J Immunol 133: 784, 1984.

12) Gillis $S$, Crabtree GR, Smith KA. Glucocorticoid induced inhibition of $T$ cell growth factor production. I. The effect of mitogen induced lymphocyte proliferation. J Immunol 123: 1624, 1979.

13) Dupont E, Huygen $\mathrm{K}$, Schandene L, et al. Influence of in vivo immunosuppressive drugs on production lymphokines. Transplantation 39: 143, 1985.

14) Scheinman RI, Cogswell PC, Lofquist AK, et al. Role of transcriptional activation of IKB in mediation of immunosuppression by glucocorticoids. Science 270: 283, 1995

15) Auphan N, DiDonato JA, Rosette C, et al. Immunosuppression by

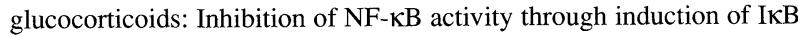
synthesis. Science 270: 286, 1995.

16) Nakazima $T$, Taniguchi $S$, Okabe $Y$, et al. A case of isolated ACTH deficiency with decrease of platelet and coagulation factors. Folia Endocrinol 72: 272, 1996 (in Japanese). 